\title{
The clinicopathological characteristics of gastric polyps and the relationship between fundic gland polyps, Helicobacter pylori infection, and proton pump inhibitors
}

\author{
Wei Gao ${ }^{1 \#}$, Yushuang Huang ${ }^{2 \#}$, Shuming $\mathrm{Lu}^{1}$, Chunyan $\mathrm{Li}^{1}$ \\ ${ }^{1}$ Department of Gastroenterology, the First Affiliated Hospital of Dalian Medical University, Dalian, China; ${ }^{2}$ The Second Department of \\ Hepatopathy, the Sixth People's Hospital of Dalian, Dalian, China \\ Contributions: (I) Conception and design: W Gao, Y Huang; (II) Administrative support: C Li; (III) Provision of study materials or patients: W Cong \\ and Z Jin; (IV) Collection and assembly of data: W Gao, Y Huang, S Lu; (V) Data analysis and interpretation: Y Huang, S Lu, C Li; (VI) Manuscript \\ writing: All authors; (VII) Final approval of manuscript: All authors. \\ \#These authors contributed equally to this work. \\ Correspondence to: Chunyan Li. Department of Gastroenterology, the First Affiliated Hospital of Dalian Medical University, 222 Zhongshan Road, \\ Xigang District, Dalian 116699, China. Email: dyyygw2012@163.com.
}

\begin{abstract}
Background: To explore the clinical characteristics of different types of gastric polyps and the relationship between fundic gland polyps, Helicobacter pylori (HP) infection, and proton pump inhibitor (PPI) use.

Methods: The clinical data of 186 patients diagnosed with gastric polyps under endoscopy were selected for retrospective analysis, and the clinical data, gastroscopy, polyp histopathology, HP infection, and PPI usage of all subjects were analyzed.

Results: Among the 186 patients with gastric polyps, there were significantly more women (131 cases) than men (55 cases), with a ratio of $2.38: 1$. PPIs were used in $78 \%$ of cases for more than 5 years. The pathological types of patients with gastric polyps in this study were fundic gland polyps, hyperplastic polyps, inflammatory fibrous polyps, and adenomatous polyps. Fundic gland polyps were mainly located in the fundus and gastric body, while hyperplastic polyps were mostly located in the gastric body $(\mathrm{P}<0.05)$. The positive rate of $H P$ infection in patients with fundic gland polyps was significantly lower than that in patients with other types of polyps $(\mathrm{P}<0.05)$. In patients with long-term use of PPIs, the incidence of fundic gland polyps increased significantly $(\mathrm{P}<0.05)$.

Conclusions: There were significant differences among the different types of gastric polyps in terms of polyp position, shape, and size. The positive rate of HP infection in patients with fundic gland polyps was low. Long-term use of PPIs ( $>5$ years) increased the incidence of fundic gland polyps to some extent. The mechanisms underlying the relationship between gastric polyps, HP infection, and the use of PPIs remain to be further studied.
\end{abstract}

Keywords: Gastric polyps; fundic gland polyps; Helicobacter pylori (HP); proton pump inhibitor (PPI)

Submitted Dec 10, 2020. Accepted for publication Jan 28, 2021.

doi: 10.21037/apm-21-39

View this article at: http://dx.doi.org/10.21037/apm-21-39

\section{Introduction}

Gastric polyps are benign lesions with a wide base or pedicle that protrude into the gastric cavity. However, according to pathological types, different types of gastric polyps have varying degrees of malignant transformation risk, and with an overall malignant transformation rate of $0.4-10 \%$ (1). Early diagnosis and active intervention are key to reducing the risk of cancer (2). With the changes in people's living habits and diet, the incidence of gastric polyps is increasing year by year, which also increases the risk of polyp 
canceration to a certain extent. Studies have shown that from 2000 to 2010, the proportion of hyperplastic polyps has declined, from $48.5 \%$ to $20.8 \%$, while the proportion of fundic gland polyps has increased from $8.8 \%$ to $66.1 \%$ (3). Fundic gland polyps have gradually replaced hyperplastic polyps as the main type of gastric polyps. Proton pump inhibitors (PPIs) play an important role in the prevention of Helicobacter pylori (HP) infection (4). However, there are no specific clinical manifestations of gastric polyps because the pathological characteristics vary across different types of gastric polyps. This study conducted a retrospective analysis of the clinicopathological characteristics of different types of gastric polyps. In addition, we examined the relationship between fundic gland polyps, HP infection, and PPI use, in order to provide a theoretical basis for preventive diagnosis and treatment, as well as to reduce the rate of polyp canceration. We present the following article in accordance with the STROBE reporting checklist (available at http:// dx.doi.org/10.21037/apm-21-39).

\section{Methods}

\section{Patient baseline information}

The clinical data of 186 patients with gastric polyps who met the diagnostic criteria from January 2018 to January 2019 were selected for retrospective analysis. The inclusion criteria were as follows: (I) patients who had not previously undergone endoscopic gastric polypectomy; (II) patients who were pathologically diagnosed with benign gastric polyps after gastric polypectomy; (III) no antibiotics, bismuth, or acid inhibitors were used in the 4 weeks before the $H P$ test, and patients had not undergone any $H P$ eradication treatment. The exclusion criteria were as follows: (I) patients with a history of gastric polypectomy, gastric malignancy, or other gastric surgery; (II) patients with a history of inflammatory bowel disease; (III) patients with gastrointestinal polyp syndrome. All procedures performed in this study involving human participants were in accordance with the Declaration of Helsinki (as revised in 2013). The study was approved by the Sixth People's Hospital of Dalian (No. 2019-105-002). Individual consent for this retrospective analysis was waived.

\section{Research methods}

Retrospective analyses of clinical data, gastroscopy, polyp histopathology, HP infection, and PPI use were performed for all research subjects. The ${ }^{13} \mathrm{C}$ urea breath test was used to determine HP infection. Judgment criteria for the use of PPIs were as follows: patients who had used PPIs for less than 1 year or needed to take the drug continuously for more than 1 month; or patients with a total medication time of more than 1 year or needed to exceed 3 months per year. The clinicopathological data of patients were compared among the different types of gastric polyps.

\section{Gastroscopy and histopathological examination}

A 260/290 electronic gastroscope (Olympus, Japan) was used for routine gastroscopy and treatment. The excised polyp was diagnosed by a specialized pathologist.

\section{Statistical analysis}

The clinical data were analyzed by SPSS 23.0 statistical software (IBM, New York, USA). The count data was analyzed by a $\chi^{2}$ test, and the measurement data was analyzed using the $t$-test and analysis of variance. $\mathrm{P}<0.05$ indicated that the difference was statistically significant.

\section{Results}

\section{General characteristics of the patients}

Among the 186 patients with gastric polyps, there were 55 males and 131 females, with a male to female ratio of 1:2.38. They had an age range of $31-84$ years old, with an average age of $55.62 \pm 11.9$ years. Patients aged between $51-70$ years old had a high incidence of gastric polyps. Clinical symptoms such as abdominal pain and reflux were common. PPIs were used for more than 5 years in $78 \%$ of cases. The average diameter of polyps was $7.7 \pm 5.6$ (ranged from 2 to $30 \mathrm{~mm}$ ), most of which were less than $6 \mathrm{~mm}$ (100 cases, accounted for $53.8 \%$ ). Patients with multiple polyps accounted for $50.5 \%$. Fundic gland polyps were the most common polyp type. The most common locations were the gastric body, antrum, and fundus, with 89 cases (47.8\%) located in the gastric body, 49 cases (26.3\%) in the antrum, and 36 cases $(19.4 \%)$ in the fundus of the stomach. The morphology of polyps were mainly broad-based polyps (Table 1).

\section{Analysis of the clinicopathological characteristics of different types of gastric polyps}

The pathological types of patients with gastric polyps in 
Table 1 Clinical and pathological features of gastric polyps

\begin{tabular}{|c|c|}
\hline Clinicopathological feature & N (\%) \\
\hline \multicolumn{2}{|l|}{ Gender } \\
\hline Male & $55(29.57)$ \\
\hline Female & $131(70.43)$ \\
\hline \multicolumn{2}{|l|}{ Age (years) } \\
\hline Male & $52.53 \pm 13.7$ \\
\hline Female & $56.92 \pm 10.8$ \\
\hline Total & $55.62 \pm 11.9$ \\
\hline \multicolumn{2}{|l|}{ Segmented age } \\
\hline$<40$ & $22(11.8)$ \\
\hline $41-50$ & $42(22.5)$ \\
\hline $51-60$ & $50(26.9)$ \\
\hline $61-70$ & $56(30.1)$ \\
\hline \multicolumn{2}{|l|}{ Occurrence frequency } \\
\hline Once & $92(49.5)$ \\
\hline Frequently & $94(50.5)$ \\
\hline \multicolumn{2}{|l|}{ Gastritis type } \\
\hline Non-atrophy & $80(43.0)$ \\
\hline Atrophy & $106(57.0)$ \\
\hline \multicolumn{2}{|l|}{ Symptom } \\
\hline None & $27(14.5)$ \\
\hline Abdominal pain & $63(33.9)$ \\
\hline Nausea & $1(0.5)$ \\
\hline Acid heartburn & $45(24.2)$ \\
\hline Epigastric discomfort & $20(10.8)$ \\
\hline Ventosity & $30(16.1)$ \\
\hline
\end{tabular}

Table 1 (continued)

this study were fundic gland polyps, hyperplastic polyps, inflammatory fibrous polyps, and adenomatous polyps. The analysis of the clinicopathological characteristics of these polyp types are shown in Table 2. There were no significant differences in sex ratio and age composition ratio between the 4 types of gastric polyps. Fundic gland polyps were mainly located in the fundus and gastric body, while hyperplastic polyps were mostly located in the gastric body $\left(\chi^{2}=77.76, \mathrm{P}<0.05\right)$. Fundic gland polyps occurred more
Table 1 (continued)

\begin{tabular}{|c|c|}
\hline Clinicopathological feature & $\mathrm{N}(\%)$ \\
\hline \multicolumn{2}{|l|}{ Polyp size } \\
\hline Diameter (mm) & $7.7 \pm 5.6[2-30]$ \\
\hline$<6 \mathrm{~mm}$ & $100(53.8)$ \\
\hline $6-10 \mathrm{~mm}$ & $54(29.0)$ \\
\hline $11-20 \mathrm{~mm}$ & $26(14.0)$ \\
\hline$>20 \mathrm{~mm}$ & $6(3.2)$ \\
\hline \multicolumn{2}{|l|}{ Polyp morphology } \\
\hline Broad-base & $142(76.3)$ \\
\hline Flat & $7(3.8)$ \\
\hline Protruding & $12(6.5)$ \\
\hline Subtropic & $25(13.4)$ \\
\hline \multicolumn{2}{|l|}{ Polyp type } \\
\hline Fundic gland & $91(48.9)$ \\
\hline Hyperplastic & $70(37.6)$ \\
\hline Inflammatory fibrous & $22(11.8)$ \\
\hline Adenomatous & $3(1.6)$ \\
\hline \multicolumn{2}{|l|}{ Polyp sites } \\
\hline Others & $1(0.5)$ \\
\hline Cardia & $4(2.2)$ \\
\hline Fundus & $36(19.4)$ \\
\hline Gastric body & $89(47.8)$ \\
\hline Gastric angle & $7(3.8)$ \\
\hline Antrum & $49(26.3)$ \\
\hline \multicolumn{2}{|l|}{ Length of PPI use } \\
\hline$\leq 5$ years & $145(78.0)$ \\
\hline$>5$ years & $41(22.0)$ \\
\hline
\end{tabular}

PPI, proton pump inhibitor.

frequently, while hyperplastic polyps and inflammatory fibrous polyps mainly occurred once $\left(\chi^{2}=8.61, \mathrm{P}<0.05\right)$. The diameter of fundic gland polyps was predominantly $<10 \mathrm{~mm}$, and were most commonly $<6 \mathrm{~mm}\left(\chi^{2}=41.335\right.$, $\mathrm{P}<0.05)$. In terms of polyp morphology, the fundic gland polyps were mainly broad-based, while the shape of hyperplastic polyps were mainly broad-based or subtropic, and the difference was statistically significant $\left(\chi^{2}=41.335\right.$, $\mathrm{P}<0.05)$. The patients with fundic gland polyps commonly 
Table 2 Clinicopathological characteristics of the different types of gastric polyps

\begin{tabular}{|c|c|c|c|c|c|c|}
\hline Gastric polyps & Fundic gland & Hyperplastic & Inflammatory fibrous & Adenomatous & $\chi^{2}$ value & $P$ value \\
\hline Male & 21 & 22 & 10 & 2 & & \\
\hline Female & 70 & 48 & 12 & 1 & & \\
\hline Age (years) & & & & & 12.224 & 0.428 \\
\hline $41-50$ & 24 & 11 & 7 & 0 & & \\
\hline $51-60$ & 24 & 17 & 8 & 1 & & \\
\hline $61-70$ & 24 & 25 & 5 & 2 & & \\
\hline$>70$ & 6 & 8 & 2 & 0 & & \\
\hline Cardia & 0 & 3 & 1 & 0 & & \\
\hline Fundus & 27 & 6 & 3 & 0 & & \\
\hline Gastric body & 61 & 22 & 5 & 1 & & \\
\hline Gastric angle & 1 & 6 & 0 & 0 & & \\
\hline Antrum & 2 & 32 & 13 & 2 & & \\
\hline Occurrence frequency & & & & & 8.61 & $0.035^{\mathrm{b}}$ \\
\hline Once & 36 & 40 & 15 & 1 & & \\
\hline Frequently & 55 & 30 & 7 & 2 & & \\
\hline Polyp morphology & & & & & 31.81 & $0.000^{d}$ \\
\hline Broad-base & 79 & 46 & 16 & 1 & & \\
\hline Flat & 4 & 0 & 2 & 1 & & \\
\hline Protruding & 2 & 7 & 3 & 0 & & \\
\hline Subtropic & 6 & 17 & 1 & 1 & & \\
\hline Gastritis type & & & & & 8.354 & $0.039^{e}$ \\
\hline Non-atrophy & 48 & 24 & 8 & 0 & & \\
\hline Atrophy & 43 & 46 & 14 & 3 & & \\
\hline
\end{tabular}

${ }^{\mathrm{a}}$, the distribution of fundic gland polyps was significantly different from that of hyperplastic polyps $\left(\chi^{2}=77.76, \mathrm{P}<0.05\right)$. ${ }^{\mathrm{b}}$, fundic gland polyps were significantly more common than hyperplastic polyps and inflammatory fibroid polyps $\left(\chi^{2}=8.61, P<0.05\right)$. ${ }^{c}$, the diameter of fundic gland polyps was more than $6 \mathrm{~mm}$, which was significantly different from other polyps $\left(\chi^{2}=41.335, P<0.05\right)$. ${ }^{d}$, fundic gland polyps were mainly broad-based polyps, while hyperplastic polyps were mainly broad-based and subtropic polyps, and the difference was statistically significant $\left(\chi^{2}=41.335, P<0.05\right)$. , compared with the other 3 types of gastric polyps, there was a significant difference in gastritis types complicated by fundic gland polyps $\left(\chi^{2}=8.354, P<0.05\right)$. 
Table 3 Relationship between the status of $H P$ infection and the length of PPI use

\begin{tabular}{|c|c|c|c|c|}
\hline & \multicolumn{2}{|c|}{$H P$ infection status } & \multicolumn{2}{|c|}{ Length of PPI use } \\
\hline Fundic gland polyps & 17 & 74 & 65 & 26 \\
\hline Other types & 42 & 53 & 80 & 15 \\
\hline$\chi^{2}$ & \multicolumn{2}{|c|}{77.814} & \multicolumn{2}{|c|}{4.419} \\
\hline
\end{tabular}

had combined non-atrophic gastritis, while patients with the other 3 kinds of gastric polyps mainly had atrophic gastritis $\left(\chi^{2}=8.354, \mathrm{P}<0.05\right)$.

\section{The relationship between fundic gland polyps, HP infection status, and the length of PPI use}

There were $17 \mathrm{HP}$ positive patients with fundic gland polyps, with a positive rate of $18.7 \%$, and $42 H P$ positive patients had other types of polyps, with a positive rate of $44.2 \%$. The results indicated that the positive rate of $H P$ infection in patients with fundic gland polyps was significantly lower than in patients with other types of polyps $\left(\chi^{2}=77.814, \mathrm{P}<0.05\right)$.

Among the 41 patients who were treated with PPIs for a long time ( $>5$ years), 26 cases were diagnosed with fundic gland polyps and 15 cases were diagnosed with other types of polyps, suggesting that patients with long-term use of PPIs had a statistically significant increase in the incidence of fundic gland polyps $\left(\chi^{2}=4.419, \mathrm{P}<0.05\right.$, Table 3$)$.

\section{Discussion}

Gastric polyps are commonly observed in women aged 40-60 years. The clinical manifestations of gastric polyps are generally atypical, and commonly include abdominal discomfort, dull pain, acid reflux, and heartburn. Some patients have severe reflux symptoms such as bile reflux, acid reflux, and heartburn $(5,6)$. Among the 186 patients in this study, the ratio of males to females was $1: 2.38$, and patients aged 51-70 years old had the highest incidence of gastric polyps. Clinical symptoms were common, including abdominal pain and reflux. However, in general, age, gender, and clinical symptoms between the different types of gastric polyps (gastric fundus polyp, hyperplastic, inflammatory fibrous, and adenomatous polyps) were not statistically significant.

The results of this study showed that fundic gland polyps tended to grow on the fundus and gastric body, with a diameter of less than $10 \mathrm{~mm}$. Polyps were mostly broadbased and occurred frequently, while hyperplastic polyps were mostly distributed on the gastric body with broadbased or subtropic morphology. The hyperplastic polyps and inflammatory polyps mostly occurred once, which was generally consistent with previous studies (7). Patients with gastric polyps often have concomitant gastritis. The results of this study suggest that patients with fundic gland polyps mostly have combined non-atrophic gastritis, while patients with the other 3 types of gastric polyps mostly have atrophic gastritis. There are currently no related reports in the domestic or foreign literature, and the underlying mechanisms still require further study. The findings of this study may have significance for the clinical screening and follow-up of patients with fundic gland polyps.

Follow-up studies with large sample sizes in recent years have shown that fundic gland polyps have replaced hyperplastic polyps as the predominant polyp type, however, the reason is not yet clear (8). HP has different infection rates among patients with different types of gastric polyps, and it has been confirmed that HP infection is related to the occurrence of hyperplastic polyps and inflammatory polyps. In contrast, the relationship between $H P$ infection and the occurrence of fundic gland polyps has not yet been elucidated. Studies have shown that HP infection is negatively correlated with the incidence of fundic gland polyps (9), and the HP infection rate in patients with fundic gland polyps is significantly lower than that in patients with hyperplastic polyps (10). However, some studies have mentioned that although $H P$ infection has been confirmed to be related to the occurrence of hyperplastic polyps and 
inflammatory fibrous polyps, there is no clear relationship between fundic gland polyps and $H P$ infection $(11,12)$. Rubio et al. suggested that patients with fundic gland polyps may have a natural lysozyme in gastric juice, which is not enough to eradicate $H P$, but can inhibit the growth of $H P$ to a certain extent (13). Watanabe et al. also suggested that $H P$ infection may be a risk factor for hyperplastic gastric polyps and may be a protective factor for fundic gland polyps (14). In this study, the positive rate of $H P$ infection in patients with fundic gland polyps was $18.7 \%$, and the positive rate of $H P$ infection in patients with other types of polyps was $44.2 \%$. This indicated that the positive rate of $H P$ infection for patients with fundic gland polyps was significantly lower than that of other types of polyps, and the occurrence of $H P$ infection might be negatively correlated with the incidence of fundic gland polyps. In addition, the canceration rate of fundic gland polyps was low, suggesting that actively eradicating $H P$ infection might play a role in preventing polyps from becoming cancerous.

PPIs can act on the $\mathrm{H}^{+}-\mathrm{K}^{+}$-ATPase, and show a strong and long-lasting acid suppression effect, which can also reduce the secretion of pepsin and protect the gastric mucosa. In recent years, PPIs have become the most widely used acid inhibitors in clinical practice. Since 1992, when JR Graham first proposed that taking PPIs could cause fundic gland polyps (15), researchers began to focus on the relationship between the use of PPIs and the occurrence of fundic gland polyps. Studies at home and abroad have shown that the long-term and extensive use of PPIs may be related to the increasing incidence of fundic gland polyps (16). Studies have reported that while PPIs inhibit gastric acid secretion, they can cause compensatory hypergastrinemia, which increases the incidence of fundic gland polyps (17). A meta-analysis by Tran-Duy et al. demonstrated that the risk of fundic gland polyps in patients using PPIs was significantly higher than that of the control group (18). In a study by Carmack et al. in 2009, it was also suggested that the increase in the incidence of fundic gland polyps might be related to the use of PPIs (7). However, the relationship between the length of PPI use and the occurrence of fundic gland polyps is not clear. A study by Vieth et al. on 2,251 patients who took PPIs for more than 4 weeks found that there was no clear association between the use of PPIs and the occurrence of fundus polyps (19). A study by Martin et al. found that the risk of fundic gland polyps in patients taking PPIs continuously for 1 year was 4-5 times that of non-users (20). Our results showed that among the 41 patients who had been using PPIs for a long time
( $>5$ years), 26 cases were diagnosed with fundic gland polyps, and 15 cases were diagnosed with other types of polyps, indicating a significant increase in the incidence of fundic gland polyps. This shows that the long-term and large-scale use of PPIs can, to some extent, increase the occurrence of fundic gland polyps. Although the canceration rate of fundic gland polyps is low, due to the wide range of indications for PPIs and the gradual increase in patients taking PPIs, the incidence of fundic gland polyps has increased accordingly, therefore the potential risk of canceration has become of increasing concern. Consequently, it is crucial to pay strict attention to the indications of PPIs and effectively followup patients who use PPIs over the long term.

In summary, this study showed that different types of gastric polyps were significantly different in terms of polyp position, shape, and size. At the same time, in patients with fundic gland polyps, the positive rate of $H P$ infection was significantly lower than in patients with other types of polyps. Furthermore, the long-term use of PPIs $(>5$ years) increased the incidence of fundic gland polyps. This may be because lysozymes in the gastric juices of patients with fundic gland polyps inhibit the growth of $H P$, or it may be that PPIs have dual effects in reducing the rate of $H P$ infection and increasing the incidence of fundic gland polyps. However, the mechanisms underlying the relationship between gastric polyps, $H P$ infection, and the use of PPIs remain to be further studied.

\section{Acknowledgments}

Funding: None.

\section{Footnote}

Reporting Checklist: The authors have completed the STROBE reporting checklist. Available at http://dx.doi. org/10.21037/apm-21-39

Data Sharing Statement: Available at http://dx.doi. org/10.21037/apm-21-39

Conflicts of Interest: All authors have completed the ICMJE uniform disclosure form (available at http://dx.doi. org/10.21037/apm-21-39). The authors have no conflicts of interest to declare.

Ethical Statement: The authors are accountable for all aspects of the work in ensuring that questions related 
to the accuracy or integrity of any part of the work are appropriately investigated and resolved. All procedures performed in this study involving human participants were in accordance with the Declaration of Helsinki (as revised in 2013). The study was approved by the Sixth People's Hospital of Dalian (No. 2019-105-002). Individual consent for this retrospective analysis was waived.

Open Access Statement: This is an Open Access article distributed in accordance with the Creative Commons Attribution-NonCommercial-NoDerivs 4.0 International License (CC BY-NC-ND 4.0), which permits the noncommercial replication and distribution of the article with the strict proviso that no changes or edits are made and the original work is properly cited (including links to both the formal publication through the relevant DOI and the license). See: https://creativecommons.org/licenses/by-nc-nd/4.0/.

\section{References}

1. Carmack SW, Genta RM, Schuler CM, et al. The current spectrum of gastric polyps: a 1-year national study of over 120,000 patients. Am J Gastroenterol 2009;104:1524-32.

2. Dobarro Castro B, Remedios Espino DR, Tejido Sandoval C, et al. Therapeutic profitability of centralising the evaluation and treatment of complex polyps. Gastroenterol Hepatol 2019;42:648-9.

3. Cao H, Wang B, Zhang Z, et al. Distribution trends of gastric polyps: an endoscopy database analysis of 24 121 northern Chinese patients. J Gastroenterol Hepatol 2012;27:1175-80.

4. Elhanafi S, Saadi M, Lou W, et al. Gastric polyps: Association with Helicobacter pylori status and the pathology of the surrounding mucosa, a cross sectional study. World J Gastrointest Endosc 2015;7:995-1002.

5. Sonnenberg A, Genta RM. Prevalence of benign gastric polyps in a large pathology database. Dig Liver Dis 2015;47:164-9.

6. Genta RM, Schuler CM, Robiou CI, et al. No association between gastric fundic gland polyps and gastrointestinal neoplasia in a study of over 100,000 patients. Clin Gastroenterol Hepatol 2009;7:849-54.

7. Carmack SW, Genta RM, Graham DY, et al. Management of gastric polyps: a pathology-based guide for gastroenterologists. Nat Rev Gastroenterol Hepatol 2009;6:331-41.

8. Borch K, Skarsgård J, Franzén L, et al. Benign gastric polyps: morphological and functional origin. Dig Dis Sci
2003;48:1292-7.

9. Cao H, Qu R, Zhang Z, et al. Sporadic fundic gland polyps are not associated with proton pump inhibitors therapy but negatively correlate with Helicobacter pylori infection in China. Chin Med J (Engl) 2014;127:1239-43.

10. Notsu T, Adachi K, Mishiro T, et al. Fundic gland polyp prevalence according to Helicobacter pylori infection status. J Gastroenterol Hepatol 2020;35:1158-62.

11. Fossmark R, Jianu CS, Martinsen TC, et al. Serum gastrin and chromogranin A levels in patients with fundic gland polyps caused by long-term proton-pump inhibition. Scand J Gastroenterol 2008;43:20-4.

12. Samarasam I, Roberts-Thomson J, Brockwell D. Gastric fundic gland polyps: a clinico-pathological study from North West Tasmania. ANZ J Surg 2009;79:467-70.

13. Rubio CA. Lysozyme Overexpression in Fundic Gland Polyps. Anticancer Res 2010;30:1021-4.

14. Watanabe N, Seno H, Nakajima T, et al. Regression of fundic gland polyps following acquisition of Helicobacter pylori. Gut 2002;51:742-5.

15. Graham JR. Gastric polyposis: onset during long-term therapy with omepra-zole. Med J Aust 1992;157:287-8.

16. Shaib YH, Rugge M, Graham DY, et al. Management of gastric polyps: an endoscopy-based approach. Clin Gastroenterol Hepatol 2013;11:1374-84.

17. Ljubicić N, Kujundzić M, Roić G, et al. Benign epithelial gastric polyps--frequency, location, and age and sex distribution. Coll Antropol 2002;26:55-60.

18. Tran-Duy A, Spaetgens B, Hoes AW, et al. Use of Proton Pump Inhibitors and Risks of Fundic Gland Polyps and Gastric Cancer: Systematic Review and Meta-analysis. Clin Gastroenterol Hepatol 2016;14:1706-19.e5.

19. Vieth M, Stolte M. Fundic gland polyps are not induced by proton pump inhibitor therapy. Am J Clin Pathol 2001;116:716-720.

20. Martin FC, Chenevix-Trench G, Yeomans ND. Systematic review with meta-analysis: fundic gland polyps and proton pump inhibitors. Aliment Pharmacol Ther 2016;44:915-25.

(English Language Editor: C. Betlazar-Maseh)

Cite this article as: Gao W, Huang Y, Lu S, Li C. The clinicopathological characteristics of gastric polyps and the relationship between fundic gland polyps, Helicobacter pylori infection, and proton pump inhibitors. Ann Palliat Med 2021;10(2):2108-2114. doi: 10.21037/apm-21-39 